\title{
BMJ Open Association between obesity indices and type 2 diabetes mellitus among middle-aged and elderly people in Jinan, China: a cross-sectional study
}

\author{
Shukang Wang, ${ }^{1}$ Wei Ma, ${ }^{2}$ Zhongshang Yuan, ${ }^{1}$ Shu-mei Wang, ${ }^{2}$ Xiangren $\mathrm{Yi}^{3}$ \\ Hongying Jia, ${ }^{4}$ Fuzhong Xue ${ }^{1}$
}

To cite: Wang S, Ma W, Yuan Z, et al. Association between obesity indices and type 2 diabetes mellitus among middle-aged and elderly people in Jinan, China: a cross-sectional study. BMJ Open 2016;6: e012742. doi:10.1136/ bmjopen-2016-012742

- Prepublication history for this paper is available online. To view these files please visit the journal online (http://dx.doi.org/10.1136/ bmjopen-2016-012742).

Received 21 May 2016 Revised 21 September 2016 Accepted 5 October 2016

CrossMark

For numbered affiliations see end of article.

Correspondence to Professor Fuzhong Xue; xuefzh@sdu.edu.cn

\section{ABSTRACT}

Background: The relationship between obesity and type 2 diabetes mellitus (T2DM) varies with geographical area and race.

Objectives: To investigate the prevalence of T2DM and the proportion of subjects with undiagnosed T2DM. In addition, to compare the associations between different obesity indices and T2DM for middle-aged and elderly people from six communities in Jinan, China.

Setting: A cross-sectional study was designed and the study subjects were chosen from blocks which were randomly selected in the 6 communities of Jinan, China in 2011-2012.

Participants: A total of 3277 residents aged $\geq 50$ years were eligible for this study, but 1563 people were excluded because they did not provide anthropometric data such as height, weight, waist circumference (WC), hip circumference, systolic blood pressure, diastolic blood pressure, fasting plasma glucose, triglyceride (TG), total cholesterol (TC) or information about their current medication use. Hence, 1714 participants were included in the final data analysis.

Results: The prevalence of T2DM among people aged $\geq 50$ years was $16.6 \%$ (19.3\% for men and $15.3 \%$ for women) and the proportion of patients with undiagnosed T2DM was 32.7\%. Compared with the lowest levels of body mass index (BMI), WC, waist-tohip ratio or waist-to-stature ratio (WSR), the ORs and $95 \%$ Cls of the highest levels for men, after adjusting for age, smoking, alcohol drinking, regular exercise, hypertension, TG and TC, were 1.607 (0.804 to 3.210), 2.189 (1.118 to 4.285$), 1.873$ (0.968 to 3.623 ) and 2.572 (1.301 to 5.083 ), respectively, and for women, 2.764 (1.622 to 4.712 ), 2.407 (1.455 to 3.985 ), 2.500 (1.484 to 4.211 ) and 2.452 (1.447 to 4.155$)$, respectively.

Conclusions: Among adults aged $\geq 50$ years in Jinan, China, the best indicator of the relationship between obesity and T2DM is WSR for men and BMI for women, respectively.

\section{Strengths and limitations of this study}

- The obesity indexes used for diabetes screening by sex for Chinese adults aged $\geq 50$ years are proposed for the first time in this study.

- Compared with a cohort study, cross-sectional design is more suitable for determining screening indexes of type 2 diabetes mellitus (T2DM).

- The best index of obesity adopted in the screening model for T2DM is different from that in the prediction model.

- Selection bias might have been present as about half of the study subjects did not take part in the physical examination.

\section{INTRODUCTION}

Type 2 diabetes mellitus (T2DM) is a worldwide public health problem that increases mortality and affects quality of life. It is estimated that the number of people with T2DM worldwide will increase from 246 million in $2012^{1}$ to 592 million by $2035 .^{2}$ The prevalence of T2DM has increased more rapidly in China, from $1 \%$ in 1980 to $5 \%$ in $2001^{3}$ and rose to $9.7 \%$ in 2008 , affecting nearly 92.4 million adults. ${ }^{4}$ An overwhelmingly serious problem is that T2DM often cannot be diagnosed until complications appear. $^{5}$ The proportion of undiagnosed cases of T2DM in China was found to be $60 \% .{ }^{4}$ It is thus important to make efforts to detect and diagnose T2DM earlier in its course, and the most suitable indexes for identifying individuals at high risk in the communities must be determined as soon as possible.

Obesity is a major independent and modifiable risk factor for T2DM and many epidemiological studies have suggested a 
progressive increase in the prevalence of T2DM with obesity. ${ }^{6}{ }^{7}$ More importantly, indexes of obesity play an unusual role in screening T2DM and determining highrisk individuals. Several measurements of obesity, including body mass index (BMI), waist circumference (WC), waist-to-hip ratio (WHR) and waist-to-stature ratio (WSR), are significantly associated with T2DM. ${ }^{8}{ }^{9} \mathrm{BMI}$ is the marker most commonly used to identify the risk of future T2DM $;{ }^{10}$ however, it cannot be used to distinguish between muscle and fat. ${ }^{11}$ Compared with BMI, central obesity indices, such as WC, WHR and WSR, appeared to be more strongly associated with T2DM. ${ }^{12}{ }^{13}$ Some studies have shown that WC is better than WHR and BMI, ${ }^{14} 15$ whereas other studies reported WSR to be the best indicator for the relationship between obesity and T2DM. ${ }^{16}{ }^{17}$ However, several studies indicated that BMI was as powerful as WC and WHR, ${ }^{18}{ }^{19}$ and BMI has been reported to be a better index than WC for the relationship between obesity and T2DM. ${ }^{20}$ Although the above four simple and economical indices of obesity have all been associated with T2DM, which of these is the best has been debated. Body fat distribution varies with age, sex and ethnicity; ${ }^{21}$ the relationship between obesity and T2DM may also differ according to these factors. Diabetes screening is paramount for adults aged $\geq 50$ years owing to their higher risks, and thus the index most suitable for representing the relationship between obesity and T2DM should be used for adults aged $\geq 50$ years in northern China.

To date, few studies have examined and compared the relationship between obesity indices and T2DM among middle-aged and elderly people in northern Chinese urban communities. Thus, we investigated the prevalence of T2DM and the proportion of people with undiagnosed T2DM and compared the associations between obesity indices and T2DM in order to determine the best obesity index to use for T2DM screening of middle-aged and elderly people in northern China.

\section{MATERIALS AND METHODS \\ Study population}

The subjects were from randomly selected blocks located in the six communities of Jinan, China in 20112012. The inclusion criteria for the participants included (1) age $\geq 50$ years, (2) the ability to answer the questionnaire and (3) residence in the selected communities for $>6$ months in the past year. A total of 3277 residents aged $\geq 50$ years completed the questionnaire in this study; 1563 people were excluded because they did not provide anthropometric data such as height, weight, WC, hip circumference, systolic blood pressure (SBP), diastolic blood pressure (DBP), fasting plasma glucose (FPG), triglyceride (TG), total cholesterol (TC) or information about their current medication use. A total of 1714 participants were included in the final data analysis.

\section{Investigation and measurements}

Trained interviewers administered a standardised questionnaire to obtain demographic information, including the subjects' age, sex, current smoking status (yes or no), current alcohol intake (yes or no) and regular exercise frequency $(<1$ time per week, 1-2 times per week, 3-4 times per week, 5-7 times per week or $\geq 8$ times per week). After an overnight fast of at least 12 hours, all subjects underwent a standardised medical examination that included routine anthropometric, clinical and laboratory tests. Blood pressure (BP) was measured in the right arm by trained examiners using a mercury sphygmomanometer according to a standard protocol. Three BP measurements were obtained with an interval of from 5 to $15 \mathrm{~min}$ and the average of the three readings was chosen as the $\mathrm{BP}$ value for each subject. The laboratory tests included TG, TC and FPG; subjects with abnormal results were assessed again on a different day. The anthropometric measurements were taken after the participants had removed their shoes and any heavy clothing or belts. Each subject's height, weight, WC and hip circumference were measured by experienced nurses. The WC was measured at the level midway between the lower rib margin and the iliac crest while the participants breathed out gently. The hip circumference measurement was taken at the maximal gluteal protrusion. The BMI, WHR and WSR were calculated as the weight $(\mathrm{kg}) /$ height $^{2}\left(\mathrm{~m}^{2}\right)$, WC $(\mathrm{cm}) / \mathrm{hip}(\mathrm{cm})$ and WC $(\mathrm{cm}) /$ stature $(\mathrm{cm})$, respectively. This study was approved by the ethics committee of the School of Public Health of Shandong University and written informed consent was obtained from each participant.

\section{Definition of obesity, hypertension, T2DM and undiagnosed T2DM}

Obesity was defined as a $\mathrm{BMI} \geq 28$ according to the standard criteria of the Chinese Obesity Working Group. ${ }^{22}$ Hypertension was defined as an $\mathrm{SBP} \geq 140 \mathrm{~mm} \mathrm{Hg}$ or a $\mathrm{DBP} \geq 90 \mathrm{~mm} \mathrm{Hg}$ at least three times or the self-reported current use of antihypertensive medication. T2DM was defined as $\mathrm{FPG} \geq 7.0 \mathrm{mmol} / \mathrm{L}$ at least twice, $\mathrm{HbAlc} \geq 6.5 \%$ and $\mathrm{FPG} \geq 7.0 \mathrm{mmol} / \mathrm{L}$, 2-hour glucose after an oral glucose tolerance test $\geq 11.1 \mathrm{mmol} / \mathrm{L}$ or anti-diabetic medication use or self-reported T2DM confirmed by either $\mathrm{FPG} \geq 7.0 \mathrm{mmol} / \mathrm{L}$ or $\mathrm{HbAlc} \geq 6.5 \%$. Undiagnosed T2DM was identified as an $\mathrm{FPG} \geq 7.0 \mathrm{mmol} / \mathrm{L}$ when neither a history of diabetes nor hypoglycaemic drug use was present. ${ }^{23}$

\section{Anthropometric indices and potential confounding factors}

Before fitting logistic regression models, the original continuous anthropometric indices, such as BMI, WC, WHR and WSR, were categorised into four levels using the three quartiles of P25, P50 and P75 as cut-off values, respectively, according to gender. Different potential confounding factors were also considered in the four logistic regression models. 


\section{Statistical analysis}

Descriptive statistics of all variables were obtained according to gender and diabetes status. Numerical data were expressed as means \pm SD or median and quartile range according to whether their distribution was normal or skewed as judged by a histogram. A twosample t-test and Wilcoxon rank sum test were used to determine the group difference. Categorical variables were expressed as percentages and a $\chi^{2}$ test was used to compare differences for categorical data. Four logistic regression models were generated according to different confounding factors. In the first model no variable was adjusted for while in the second model adjustment for age only was made. The third model contained adjustments for continuous age, smoking (yes or no), alcohol drinking (yes or no) and regular exercise frequency $(<1$ time per week, 1-2 times per week, 3-4 times per week, $5-7$ times per week or $\geq 8$ times per week); adjustments for hypertension (yes or no), continuous TG and cholesterol were added to the fourth model. Categorical BMI, WC, WHR and WSR values were the independent variables in the four models. The areas under the receiver operating characteristic curves (AUCs) and their 95\% CIs were computed for BMI, WC, WHR or WSR in the four models, respectively, according to gender. $\mathrm{p}<0.05$ was considered statistically significant and SPSS (V.20.0) was used to perform the analyses.

\section{RESULTS}

A total of 1714 people (555 men and 1159 women) aged $\geq 50$ years were included in this study. The characteristics of the study participants according to gender are summarised in table 1 . The median age was 64.00 (14.00) years for men and $62.00(15.00)$ years for women; a significant difference for age was found between men and women $(p=0.035)$. Participants in the male group were taller, heavier, had a greater WC, WHR, DBP and FPG, a higher prevalence of hypertension and T2DM and a higher incidence of a current alcohol drinking and smoking than those in female group $(\mathrm{p}<0.05)$. However, WSR, TG and TC measurements and the prevalence of obesity in the female group were significantly higher than those in the male group $(\mathrm{p}<0.05)$.

Table 2 shows a comparison of characteristics of the study participants between the diabetic and non-diabetic groups. Participants in the diabetic group were older,

Table 1 Summary statistics and comparison of anthropometric measurements according to gender

\begin{tabular}{|c|c|c|c|c|}
\hline Characteristics & Men $(n=555)$ & Women $(n=1159)$ & Total $(n=1714)$ & p Value \\
\hline Age (years), median & $64.00(14.00)$ & $62.00(15.00)$ & $63.00(15.00)$ & 0.035 \\
\hline Height $(\mathrm{cm})$ & $169.07 \pm 5.90$ & $157.29 \pm 5.78$ & $161.11 \pm 8.01$ & $<0.001$ \\
\hline Weight (kg) & $72.32 \pm 10.20$ & $62.87 \pm 9.75$ & $65.93 \pm 10.84$ & $<0.001$ \\
\hline Hip (cm) & $100.75 \pm 6.81$ & $100.68 \pm 8.31$ & $100.70 \pm 7.86$ & 0.074 \\
\hline WC $(\mathrm{cm})$ & $91.36 \pm 9.40$ & $87.13 \pm 10.13$ & $88.50 \pm 10.09$ & $<0.001$ \\
\hline BMI $\left(\mathrm{kg} / \mathrm{m}^{2}\right)$ & $25.27 \pm 3.11$ & $25.40 \pm 3.68$ & $25.36 \pm 3.50$ & 0.434 \\
\hline WHR & $0.91 \pm 0.06$ & $0.86 \pm 0.06$ & $0.88 \pm 0.07$ & $<0.001$ \\
\hline WSR & $0.54 \pm 0.06$ & $0.55 \pm 0.07$ & $0.55 \pm 0.06$ & $<0.001$ \\
\hline $\mathrm{SBP}(\mathrm{mm} \mathrm{Hg})$ & $138.00(30.00)$ & $130.00(30.00)$ & $130.00(30.00)$ & 0.131 \\
\hline $\mathrm{DBP}(\mathrm{mm} \mathrm{Hg})$ & $85.00(10.00)$ & $80.00(15.00)$ & $80.00(12.00)$ & $<0.001$ \\
\hline $\mathrm{FPG}(\mathrm{mg} / \mathrm{dL})$ & $5.45(1.29)$ & $5.36(0.96)$ & $5.38(1.04)$ & 0.047 \\
\hline $\mathrm{TG}(\mathrm{mg} / \mathrm{dL})$ & $1.18(0.87)$ & $1.26(0.85)$ & $1.24(0.85)$ & 0.012 \\
\hline $\mathrm{TC}(\mathrm{mg} / \mathrm{dL})$ & $4.92 \pm 0.87$ & $5.40 \pm 1.02$ & $5.25 \pm 1.00$ & $<0.001$ \\
\hline Smoking, n (\%) & $214(38.6)$ & $39(3.4)$ & $253(14.8)$ & $<0.001$ \\
\hline Alcohol drinking, $\mathrm{n}(\%)$ & $179(32.3)$ & $23(2.0)$ & $202(11.8)$ & $<0.001$ \\
\hline \multicolumn{5}{|l|}{ Regular exercise, n (\%) } \\
\hline$<1$ Time per week & $78(14.1)$ & $196(16.9)$ & $274(16.0)$ & 0.131 \\
\hline 1 2 Times per week & $40(7.2)$ & $63(5.4)$ & $103(6.0)$ & 0.149 \\
\hline 3 4 Times per week & $55(9.9)$ & $120(10.4)$ & $175(10.2)$ & 0.776 \\
\hline 5 7 Times per week & $247(44.5)$ & $514(44.3)$ & $761(44.4)$ & 0.952 \\
\hline$\geq 8$ Times per week & $135(24.3)$ & $266(23.0)$ & $401(23.4)$ & 0.530 \\
\hline Obesity, n (\%) & $92(16.6)$ & $254(21.9)$ & $346(20.2)$ & 0.010 \\
\hline Hypertension, n (\%) & $376(67.7)$ & $681(58.8)$ & $1057(61.7)$ & $<0.001$ \\
\hline T2DM, n (\%) & 107 (19.3) & $177(15.3)$ & $284(16.6)$ & 0.037 \\
\hline Undiagnosed T2DM, n (\%)* & $38(35.5)$ & $55(31.1)$ & $93(32.7)$ & 0.440 \\
\hline
\end{tabular}

Results are shown as means \pm SD unless stated otherwise.

The comparison of characteristics between men and women (unpaired Student's t-test or Wilcoxon rank sum test for numerical data, $\chi^{2}$ test for categorical data).

*Undiagnosed T2DM was calculated as the number of patients with undiagnosed T2DM divided by the total number of patients with T2DM in this survey.

BMI, body mass index; DBP, diastolic blood pressure; FPG, fasting plasma glucose; Hip, hip circumference; SBP, systolic blood pressure; T2DM, type 2 diabetes mellitus; TC, total cholesterol; TG, triglyceride; WC, waist circumference; WHR, waist-to-hip ratio; WSR, waist-to-stature ratio. 
Table 2 Summary statistics and a comparison of characteristics between the diabetic and non-diabetic groups

\begin{tabular}{|c|c|c|c|}
\hline Characteristics & Diabetic $(n=284)$ & Non-diabetic $(n=1430)$ & p Value \\
\hline Age (years), median & $64.00(13.75)$ & $63.00(15.00)$ & 0.021 \\
\hline Height (cm) & $161.56 \pm 7.67$ & $161.02 \pm 8.08$ & 0.300 \\
\hline Weight (kg) & $68.64 \pm 9.53$ & $65.39 \pm 11.00$ & $<0.001$ \\
\hline Hip (cm) & $102.35 \pm 7.70$ & $100.38 \pm 7.85$ & $<0.001$ \\
\hline WC (cm) & $91.97 \pm 10.44$ & $87.84 \pm 9.89$ & $<0.001$ \\
\hline BMI $\left(\mathrm{kg} / \mathrm{m}^{2}\right)$ & $26.30 \pm 3.30$ & $25.17 \pm 3.51$ & $<0.001$ \\
\hline WHR & $0.90 \pm 0.07$ & $0.87 \pm 0.06$ & $<0.001$ \\
\hline WSR & $0.57 \pm 0.07$ & $0.55 \pm 0.06$ & $<0.001$ \\
\hline $\mathrm{SBP}(\mathrm{mm} \mathrm{Hg})$ & $140.00(25.75)$ & $130.00(30.00)$ & 0.007 \\
\hline $\mathrm{DBP}(\mathrm{mm} \mathrm{Hg})$ & $80.00(14.00)$ & $80.00(10.00)$ & 0.535 \\
\hline $\mathrm{FPG}(\mathrm{mg} / \mathrm{dL})$ & $7.88(2.55)$ & $5.26(0.78)$ & $<0.001$ \\
\hline $\mathrm{TG}(\mathrm{mg} / \mathrm{dL})$ & $1.59(1.11)$ & $1.19(0.81)$ & $<0.001$ \\
\hline $\mathrm{TC}(\mathrm{mg} / \mathrm{dL})$ & $5.39 \pm 1.34$ & $5.22 \pm 0.91$ & 0.034 \\
\hline Men, n (\%) & 107 (37.7) & 448 (31.3) & 0.037 \\
\hline Smoking, n (\%) & $39(13.7)$ & $214(15.0)$ & 0.593 \\
\hline Alcohol drinking, $\mathrm{n}(\%)$ & $23(8.1)$ & 179 (12.5) & 0.035 \\
\hline \multicolumn{4}{|l|}{ Regular exercise, n (\%) } \\
\hline$<1$ time per week & $51(18.0)$ & $223(15.6)$ & 0.321 \\
\hline 1 2 Times per week & $13(4.6)$ & $90(6.3)$ & 0.266 \\
\hline 3 4 Times per week & $29(10.2)$ & $146(10.2)$ & 0.999 \\
\hline 5 7 Times per week & $128(45.1)$ & $633(44.3)$ & 0.803 \\
\hline$\geq 8$ Times per week & $63(22.2)$ & $338(23.6)$ & 0.597 \\
\hline Obesity, n (\%) & $74(26.1)$ & 272 (19.0) & 0.007 \\
\hline Hypertension, n (\%) & $191(67.3)$ & $866(60.6)$ & 0.034 \\
\hline
\end{tabular}

Results are shown as means \pm SD unless stated otherwise.

The comparison of characteristics between diabetic and non-diabetic (unpaired Student's $t$-test or Wilcoxon rank sum test for numerical data, $\chi^{2}$ test for categorical data).

BMI, body mass index; DBP, diastolic blood pressure; FPG, fasting plasma glucose; Hip, hip circumference; SBP, systolic blood pressure; TC, total cholesterol; TG, triglyceride; WC, waist circumference; WHR, waist-to-hip ratio; WSR, waist-to-stature ratio.

heavier, had higher hip circumference, WC, BMI, WHR, WSR, SBP, FPG, TG and TC measurements, a higher prevalence of hypertension and obesity and a higher proportion of the men than those in the non-diabetic group $(p<0.05)$. However, the incidence of current alcohol drinking in the non-diabetic group was significantly higher than that in the diabetic group $(\mathrm{p}<0.05)$.

Table 3 compares the associations between obesity indices and T2DM, after adjusting for potential confounding factors, respectively, in the male group. Compared with the lowest BMI, WC, WHR or WSR levels, the ORs and $95 \%$ CIs of the highest were 1.773 (0.943 to 3.333), 2.343 (1.247 to 4.404 ), 1.899 (1.019 to 3.539 ) and 3.003 (1.614 to 5.591), respectively, without adjustment for any variables. The ORs and 95\% CIs of the highest levels were 1.861 (0.985 to 3.541$), 2.241$ (1.189 to 4.226$), 1.806$ (0.965 to 3.378) and 2.782 (1.482 to 5.224), respectively, with adjustment for age. The ORs and $95 \%$ CIs of the highest levels were 2.000 (1.036 to 3.861 ), 2.570 (1.343 to 4.918 ), 2.145 (1.126 to 4.085 ) and 3.183 (1.661 to 6.101), respectively, with adjustment for age, smoking, alcohol drinking and regular exercise. The ORs and $95 \%$ CIs of the highest levels were 1.607 (0.804 to 3.210$), 2.189$ (1.118 to 4.285 ), 1.873 (0.968 to 3.623 ) and 2.572 (1.301 to 5.083), respectively, with adjustment for age, smoking, alcohol drinking, regular exercise, hypertension, TG and TC.
Table 4 illustrates the association between obesity indices and T2DM, after adjusting for potential confounding factors, respectively, in the female group. Compared with the lowest BMI, WC, WHR or WSR levels, the ORs and 95\% CIs of the highest were 3.183 (1.905 to 5.319), 2.587 (1.626 to 4.115), 2.651 (1.625 to 4.327 ) and 2.652 (1.644 to 4.277 ), respectively, without adjustment for any variables. The ORs and $95 \%$ CIs of the highest levels were 3.161 (1.890 to 5.288), 2.697 (1.661 to 4.378), 2.801 (1.677 to 4.679 ) and 2.862 (1.720 to 4.763$)$, respectively, with adjustment for age. The ORs and $95 \%$ CIs of the highest levels were 3.230 (1.926 to 5.415 ), 2.755 (1.693 to 4.484 ), 2.816 (1.685 to 4.706 ) and 2.891 (1.733 to 4.822), with adjustment for age, smoking, alcohol drinking and regular exercise. The ORs and 95\% CIs of the highest levels were 2.764 (1.622 to 4.712 ), 2.407 (1.455 to 3.985 ), 2.500 (1.484 to 4.211 ) and 2.452 (1.447 to 4.155 ), respectively, with adjustment for age, smoking, alcohol drinking, regular exercise, hypertension, TG and TC.

Table 5 shows the AUCs for BMI, WC, WHR and WSR according to gender, respectively, in the four models. The AUCs of the WSR for men in the four models were 0.608 (0.549 to 0.668$), 0.614$ (0.554 to 0.675$), 0.679$ (0.622 to 0.735$), 0.703$ (0.648 to 0.758$)$, respectively. The AUC of the WSR was larger than the AUC for BMI, WC and WHR for the men. The BMI AUCs for women 
Table $3 \mathrm{OR}$ and $95 \% \mathrm{Cl}$ of the presence of T2DM according to quartiles of anthropometric indicators for men

\begin{tabular}{|c|c|c|c|c|c|c|}
\hline Variable & $\mathbf{n}$ & $\%$ & Model 1 & Model 2 & Model 3 & Model 4 \\
\hline \multicolumn{7}{|c|}{ BMI $\left(\mathrm{kg} / \mathrm{m}^{2}\right)$} \\
\hline$<23.43$ & 138 & 24.9 & Reference & Reference & Reference & Reference \\
\hline $23.43-$ & 140 & 25.2 & $1.566(0.828$ to 2.961$)$ & $1.557(0.821$ to 2.954$)$ & $1.584(0.820$ to 3.057$)$ & $1.417(0.725$ to 2.769$)$ \\
\hline $25.34-$ & 141 & 25.4 & $1.693(0.901$ to 3.179$)$ & $1.811(0.959$ to 3.421$)$ & 1.861 (0.964 to 3.592$)$ & $1.686(0.861$ to 3.301$)$ \\
\hline 27.08 & 136 & 24.5 & $1.773(0.943$ to 3.333$)$ & $1.861(0.985$ to 3.541$)$ & $2.000(1.036$ to 3.861$)$ & $1.607(0.804$ to 3.210$)$ \\
\hline \multicolumn{7}{|l|}{ WC (cm) } \\
\hline$<86$ & 160 & 28.8 & Reference & Reference & Reference & Reference \\
\hline $86-$ & 141 & 25.4 & $1.839(0.976$ to 3.463$)$ & $1.824(0.967$ to 3.441$)$ & $1.776(0.931$ to 3.386$)$ & $1.619(0.842$ to 3.114$)$ \\
\hline 92- & 129 & 23.2 & 2.249 (1.198 to 4.220$)$ & $2.242(1.193$ to 4.216$)$ & 2.277 (1.195 to 4.339$)$ & $1.988(1.024$ to 3.861$)$ \\
\hline 97- & 125 & 22.5 & $2.343(1.247$ to 4.404$)$ & 2.241 (1.189 to 4.226$)$ & 2.570 (1.343 to 4.918$)$ & 2.189 (1.118 to 4.285$)$ \\
\hline \multicolumn{7}{|l|}{ WHR } \\
\hline$<0.87$ & 136 & 24.5 & Reference & Reference & Reference & Reference \\
\hline $0.87-$ & 142 & 25.6 & $1.190(0.616$ to 2.301$)$ & $1.173(0.606$ to 2.271$)$ & $1.223(0.620$ to 2.410$)$ & $1.088(0.546$ to 2.168$)$ \\
\hline $0.91-$ & 137 & 24.7 & $1.877(1.004$ to 3.509$)$ & $1.790(0.954$ to 3.360$)$ & $1.837(0.967$ to 3.490$)$ & $1.581(0.821$ to 3.047$)$ \\
\hline $0.94-$ & 140 & 25.2 & 1.899 (1.019 to 3.539$)$ & $1.806(0.965$ to 3.378$)$ & 2.145 (1.126 to 4.085$)$ & $1.873(0.968$ to 3.623$)$ \\
\hline \multicolumn{7}{|l|}{ WSR } \\
\hline$<0.51$ & 141 & 25.4 & Reference & Reference & Reference & Reference \\
\hline $0.51-$ & 136 & 24.5 & $1.485(0.755$ to 2.921$)$ & $1.449(0.735$ to 2.857$)$ & $1.495(0.745$ to 3.001$)$ & $1.297(0.637$ to 2.640$)$ \\
\hline $0.54-$ & 134 & 24.1 & 1.673 (0.858 to 3.262$)$ & $1.618(0.827$ to 3.162$)$ & $1.738(0.875$ to 3.452$)$ & 1.581 (0.789 to 3.167$)$ \\
\hline $0.57-$ & 144 & 25.9 & $3.003(1.614$ to 5.591$)$ & $2.782(1.482$ to 5.224$)$ & $3.183(1.661$ to 6.101$)$ & $2.572(1.301$ to 5.083$)$ \\
\hline
\end{tabular}

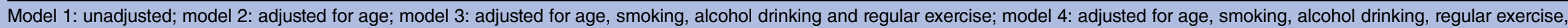
hypertension, TG and TC.

BMI, body mass index; T2DM, type 2 diabetes mellitus; TC, total cholesterol; TG, triglyceride; WC, waist circumference; WHR, waist-to-hip ratio; WSR, waist-to-stature ratio. 
Table 4 OR and $95 \% \mathrm{Cl}$ for the presence of T2DM according to quartiles of anthropometric indicators for women

\begin{tabular}{|c|c|c|c|c|c|c|}
\hline Variable & $\mathbf{n}$ & $\%$ & Model 1 & Model 2 & Model 3 & Model 4 \\
\hline \multicolumn{7}{|c|}{ BMI $\left(\mathrm{kg} / \mathrm{m}^{2}\right)$} \\
\hline$<22.96$ & 296 & 25.5 & Reference & Reference & Reference & Reference \\
\hline 22.96- & 296 & 25.5 & 2.240 (1.322 to 3.797$)$ & 2.233 (1.317 to 3.785$)$ & 2.220 (1.307 to 3.770$)$ & $1.936(1.130$ to 3.316$)$ \\
\hline $25.30-$ & 288 & 24.8 & 2.374 (1.402 to 4.019$)$ & 2.370 (1.400 to 4.012$)$ & 2.396 (1.413 to 4.063$)$ & 2.006 (1.169 to 3.442$)$ \\
\hline $27.77-$ & 279 & 24.1 & 3.183 (1.905 to 5.319$)$ & 3.161 (1.890 to 5.288$)$ & 3.230 (1.926 to 5.415$)$ & 2.764 (1.622 to 4.712$)$ \\
\hline \multicolumn{7}{|l|}{ WC (cm) } \\
\hline$<81$ & 334 & 28.8 & Reference & Reference & Reference & Reference \\
\hline $81-$ & 305 & 26.3 & $1.377(0.844$ to 2.246$)$ & $1.399(0.855$ to 2.289$)$ & $1.421(0.867$ to 2.329$)$ & $1.277(0.771$ to 2.117$)$ \\
\hline $88-$ & 262 & 22.6 & 1.994 (1.236 to 3.217$)$ & $2.043(1.258$ to 3.318$)$ & 2.056 (1.264 to 3.345$)$ & 1.808 (1.094 to 2.988$)$ \\
\hline 94- & 258 & 22.3 & 2.587 (1.626 to 4.115$)$ & 2.697 (1.661 to 4.378$)$ & 2.755 (1.693 to 4.484$)$ & 2.407 (1.455 to 3.985$)$ \\
\hline \multicolumn{7}{|c|}{ 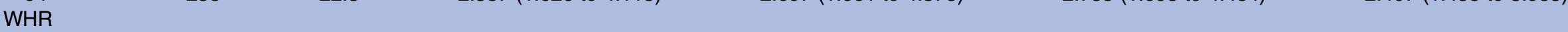 } \\
\hline$<0.83$ & 301 & 26.0 & Reference & Reference & Reference & Reference \\
\hline $0.83-$ & 295 & 25.5 & 1.685 (1.009 to 2.813$)$ & $1.710(1.022$ to 2.861$)$ & 1.705 (1.018 to 2.855$)$ & 1.589 (0.942 to 2.680$)$ \\
\hline $0.86-$ & 283 & 24.4 & $2.178(1.321$ to 3.589$)$ & $2.255(1.356$ to 3.751$)$ & $2.305(1.383$ to 3.842$)$ & 1.998 (1.187 to 3.362$)$ \\
\hline $0.91-$ & 280 & 24.2 & 2.651 (1.625 to 4.327$)$ & 2.801 (1.677 to 4.679 ) & 2.816 (1.685 to 4.706$)$ & 2.500 (1.484 to 4.211$)$ \\
\hline \multicolumn{7}{|l|}{ WSR } \\
\hline$<0.51$ & 302 & 26.1 & Reference & Reference & Reference & Reference \\
\hline $0.51-$ & 299 & 25.8 & $1.581(0.985$ to 2.609$)$ & $1.620(0.978$ to 2.681$)$ & $1.606(0.969$ to 2.661$)$ & 1.384 (0.823 to 2.362$)$ \\
\hline $0.56-$ & 285 & 24.6 & 1.765 (1.073 to 2.904$)$ & 1.843 (1.109 to 3.062$)$ & $1.846(1.110$ to 3.070$)$ & 1.595 (0.945 to 2.693$)$ \\
\hline $0.60-$ & 273 & 23.6 & 2.652 (1.644 to 4.277$)$ & $2.862(1.720$ to 4.763$)$ & 2.891 (1.733 to 4.822$)$ & 2.452 (1.447 to 4.155$)$ \\
\hline
\end{tabular}

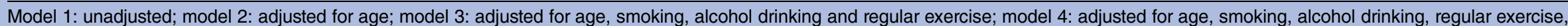
hypertension, TG and TC.

BMI. body mass index; T2DM, type 2 diabetes mellitus; TC, total cholesterol; TG, triglyceride; WC, waist circumference; WHR, waist-to-hip ratio; WSR, waist-to-stature ratio. 
Table $5 \mathrm{AUC}$ and $95 \% \mathrm{Cl}$ of the prediction of T2DM according to anthropometric indicators by gender

\begin{tabular}{lllll}
\hline Variable & Model 1 & Model 2 & Model 3 & Model 4 \\
\hline Men & & & & \\
BMI $\left(\mathrm{kg} / \mathrm{m}^{2}\right)$ & $0.552(0.493$ to 0.611$)$ & $0.586(0.523$ to 0.649$)$ & $0.663(0.607$ to 0.719$)$ & $0.692(0.636$ to 0.747$)$ \\
WC $(\mathrm{cm})$ & $0.584(0.526$ to 0.642$)$ & $0.610(0.551$ to 0.669$)$ & $0.670(0.615$ to 0.725$)$ & $0.694(0.639$ to 0.749$)$ \\
WHR & $0.572(0.513$ to 0.631$)$ & $0.596(0.539$ to 0.652$)$ & $0.659(0.604$ to 0.713$)$ & $0.690(0.636$ to 0.744$)$ \\
WSR & $0.608(0.549$ to 0.668$)$ & $0.614(0.554$ to 0.675$)$ & $0.679(0.622$ to 0.735$)$ & $0.703(0.648$ to 0.758$)$ \\
Women & & & \\
BMI $\left(\mathrm{kg} / \mathrm{m}^{2}\right)$ & $0.599(0.555$ to 0.642$)$ & $0.604(0.560$ to 0.648$)$ & $0.618(0.575$ to 0.661$)$ & $0.669(0.627$ to 0.711$)$ \\
WC $(\mathrm{cm})$ & $0.600(0.555$ to 0.644$)$ & $0.602(0.557$ to 0.647$)$ & $0.609(0.565$ to 0.654$)$ & $0.662(0.622$ to 0.703$)$ \\
WHR & $0.594(0.550$ to 0.638$)$ & $0.596(0.550$ to 0.641$)$ & $0.611(0.567$ to 0.656$)$ & $0.668(0.627$ to 0.709$)$ \\
WSR & $0.592(0.547$ to 0.637$)$ & $0.594(0.549$ to 0.640$)$ & $0.607(0.563$ to 0.652$)$ & $0.663(0.622$ to 0.704$)$ \\
\hline
\end{tabular}

Model 1: unadjusted; model 2: adjusted for age; model 3: adjusted for age, smoking, alcohol drinking and regular exercise; model 4: adjusted for age, smoking, alcohol drinking, regular exercise, hypertension, TG and TC.

AUC, areas under the receiver operating characteristic curves; BMI, body mass index; T2DM, type 2 diabetes mellitus; TC, total cholesterol;

TG, triglyceride; WC, waist circumference; WHR, waist-to-hip ratio; WSR, waist-to-stature ratio.

were 0.604 ( 0.560 to 0.648$), 0.618$ (0.575 to 0.661$)$, 0.669 (0.627 to 0.711$)$ in models 2,3 and 4, respectively, and was larger than that for the WC, WHR and WSR.

\section{DISCUSSION}

The prevalence of T2DM has been increasing and the current situation is especially serious in Asia and China. ${ }^{24} 25$ The prevalence of T2DM was $19.3 \%$ for men and $15.3 \%$ for women in adults $\geq 50$ years in our study. This prevalence was higher than that of $11.6 \%$ for all of China, ${ }^{26} 12.7 \%$ for Harbin, ${ }^{27} 5.5 \%$ for Guangzhou, ${ }^{28}$ $6.7 \%$ for Shanghai, ${ }^{29} 5.3 \%$ for Haikou ${ }^{30}$ and $7.6 \%$ in the Three Gorges Reservoir Region. ${ }^{31}$ T2DM prevalence increased with age, in men more than women, in urban more than rural areas and in the north more than the south of China. ${ }^{4}{ }^{26}$ Our findings differed from those of the above study because we studied an older group in northern and urban locations. A more thorough investigation is, therefore, needed that examines many age groups and geographical regions.

The proportion of patients with undiagnosed T2DM declined with age. ${ }^{32}$ The proportion of undiagnosed patients with T2DM was $32.7 \%$ in our study, which was lower than the $60 \%$ found in a nationwide study of China. ${ }^{4}$ The high proportion of patients with undiagnosed T2DM will increase the long-term cost of the disease in China. ${ }^{33}$ Early intervention can prevent or delay T2DM onset. ${ }^{34}{ }^{35}$ Routine screening for undiagnosed T2DM is especially important and should be implemented as soon as possible in China. Owing to the economic and demographic situation of China, simple, economical and convenient indicators should be found to identify the population that is at a high risk of developing T2DM to reduce costs.

Anthropometric indices of the relationship between obesity and T2DM would provide effective screening for T2DM. ${ }^{36}$ However, the best index (BMI, WC, WHR or WSR) for indicating the relationship between obesity and T2DM is unknown and the conclusions are not uniform. The relationship between obesity and T2DM may differ according to age, sex or race ${ }^{37}$ and according to which indicator is used to best represent the relationship between obesity and T2DM. Thus, in this study, we examined the relationship between obesity and T2DM among people aged $\geq 50$ years in Jinan, China. Age, height, weight, WC, WHR, WSR, DBP, FPG, TG, TC measurements and the prevalence of obesity, hypertension, smoking and alcohol drinking differed significantly according to gender, suggesting that gender is a strong confounder. Subgroup analyses were conducted in men and women to show and compare the relationships between obesity and T2DM. Our final sample included more women than men; this might have been because the women were more willing to comply with the requirements of the survey and the physical examination than men.

According to our results, the best indicator for the relationship between obesity and T2DM was WSR for men and BMI for women. Most studies in China, including two studies from northeast China, ${ }^{38} 39$ a study involving three cities of northern China and four cities of southern China, ${ }^{40}$ and another study from the China National Nutrition and Health Survey, ${ }^{36}$ confirmed that WSR was better than BMI, WC and WHR. The above results were also found in other Asian countries, such as Iran, ${ }^{41}$ Korea $^{42}$ and Japan. ${ }^{43}$ Our study included an older study population and a study from Changchun in northeast China included adults aged $\geq 40$ years. However, other studies included adults aged $\geq 20$ years. The results for the men were the same as those in previous studies; however, BMI was the best indicator for the relationship between obesity and T2DM for the women in our study. Our results for the women differed from those of previous studies, possibly for the following reasons. First, the average age of the subjects in our study was approximately 63 years and age-related declines in muscle and increases in adipose tissues have been demonstrated; ${ }^{44}$ second, some studies found that WC was greater in men than women, ${ }^{45}{ }^{46}$ which 
suggested that fat in men was focused more on the waist rather than throughout the body, whereas fat tissue in the women was spread throughout the body. The above confirmed that older women have more peripheral fat than men; ${ }^{47}$ this may explain why BMI is better than the other indicators in elderly women.

T2DM screening and prediction are both important in view of the serious situation. The best index of obesity adopted in a screening model for T2DM differs from that in a prediction model. This means we must be aware that the best predictive indexes are from prospective cohort studies, whereas the best screening indexes are from cross-sectional studies. Thus a cross-sectional study was performed to determine the best obesity indicator for T2DM screening in this study. In addition, the relationship between obesity and T2DM varies with age, sex and ethnicity. ${ }^{37}$ T2DM screening is important for adults aged $\geq 50$ years because they have higher risks. No study has yet focused on the relationship between obesity and T2DM for Chinese people aged $\geq 50$ years. In our study, the obesity indexes used for T2DM screening by sex for Chinese adults $\geq 50$ years are proposed. This conclusion remains to be confirmed in further cross-sectional studies by age group.

Our investigation had several limitations. First, our study had a cross-sectional design, which can be used to explore the associations between obesity and T2DM but cannot be used to explore causations. However, it is suitable for identifying populations that are at a high risk of T2DM. A prospective cohort study would be useful to determine the predictive indicators of T2DM. Second, about half of the sample in this study did not take part in the physical examination, which might have created a selection bias.

In conclusion, WSR and BMI were the best indicators of the relationship between obesity and T2DM for men and women, respectively, among adults aged $\geq 50$ years in Jinan, China. The FPG of adults aged $\geq 50$ years should be monitored regularly to identify patients with T2DM using the WSR for men and BMI for women.

\section{Author affiliations \\ ${ }^{1}$ Department of Biostatistics, School of Public Health, Shandong University, Jinan, China \\ ${ }^{2}$ Department of Epidemiology, School of Public Health, Shandong University, Jinan, China \\ ${ }^{3}$ The College of Physical Education, Shandong University, Jinan, China \\ ${ }^{4}$ The Second Hospital of Shandong University, Jinan, China}

Acknowledgements We thank all subjects who participated in the study, and the staff working at the communities in Jinan, China.

Contributors SW and FX: conceived and designed the research; SW, WM, S-mW and $X Y$ : collected the data; SW and HJ: analyzed the data; SW, ZY and FX: wrote the paper.

Funding This work was supported by two grants from the National Natural Science Fund (No. 81102191) of China and the Independent Innovation Foundation of Shandong University 2012JC035. The funders had no role in the study design, data collection and analysis, decision to publish or preparation of the manuscript.
Competing interests None declared.

\section{Patient consent Obtained.}

Ethics approval This study was approved by the ethics committee of the School of Public Health of Shandong University.

Provenance and peer review Not commissioned; externally peer reviewed.

Data sharing statement No additional data are available.

Open Access This is an Open Access article distributed in accordance with the Creative Commons Attribution Non Commercial (CC BY-NC 4.0) license, which permits others to distribute, remix, adapt, build upon this work noncommercially, and license their derivative works on different terms, provided the original work is properly cited and the use is non-commercial. See: http:// creativecommons.org/licenses/by-nc/4.0/

\section{REFERENCES}

1. Garduno-Diaz SD, Khokhar S. Prevalence, risk factors and complications associated with type 2 diabetes in migrant South Asians. Diabetes Metab Res Rev 2012;28:6-24.

2. Guariguata L, Whiting DR, Hambleton I, et al. Global estimates of diabetes prevalence for 2013 and projections for 2035. Diabetes Res Clin Pract 2014;103:137-49.

3. Gu D, Reynolds K, Duan X, et al. Prevalence of diabetes and impaired fasting glucose in the Chinese adult population: International Collaborative Study of Cardiovascular Disease in Asia (InterASIA). Diabetologia 2003;46:1190-8.

4. Yang $\mathrm{W}, \mathrm{Lu} \mathrm{J}$, Weng J, et al. Prevalence of diabetes among men and women in China. N Engl J Med 2010;362:1090-101.

5. American Diabetes Association. Standards of medical care in diabetes-2006. Diabetes Care 2006;29(Suppl 1):S4-42.

6. Boffetta $\mathrm{P}, \mathrm{McL}$ erran $\mathrm{D}, \mathrm{Chen} \mathrm{Y}$, et al. Body mass index and diabetes in Asia: a cross-sectional pooled analysis of 900,000 individuals in the Asia cohort consortium. PLOS ONE 2011;6: e19930.

7. Ma RC, Chan JC. Type 2 diabetes in East Asians: similarities and differences with populations in Europe and the United States. Ann N Y Acad Sci 2013;1281:64-91.

8. Siddiquee T, Bhowmik B, Karmaker RK, et al. Association of general and central obesity with diabetes and prediabetes in rural Bangladeshi population. Diabetes Metab Syndr 2015;9:247-51.

9. Sayeed MA, Mahtab H, Latif ZA, et al. Waist-to-height is a better obesity index than body mass index and waist-to-hip ratio for predicting diabetes, hypertension and lipidemia. Bangladesh Med Res Counc Bull 2003;29:1-10.

10. Bastien M, Poirier P, Lemieux I, et al. Overview of epidemiology and contribution of obesity to cardiovascular disease. Prog Cardiovasc Dis 2014;56:369-81.

11. Romero-Corral A, Montori VM, Somers VK, et al. Association of body weight with total mortality and with cardiovascular events in coronary artery disease: a systematic review of cohort studies. Lancet 2006;368:666-78.

12. Lee CM, Huxley RR, Wildman RP, et al. Indices of abdominal obesity are better discriminators of cardiovascular risk factors than BMI: a meta-analysis. J Clin Epidemiol 2008;61:646-53.

13. Goh LG, Dhaliwal SS, Welborn TA, et al. Anthropometric measurements of general and central obesity and the prediction of cardiovascular disease risk in women: a cross-sectional study. BMJ Open 2014;4:e004138.

14. Wang Y, Rimm EB, Stampfer MJ, et al. Comparison of abdominal adiposity and overall obesity in predicting risk of type 2 diabetes among men. Am J Clin Nutr 2005;81:555-63.

15. Zhu S, Heymsfield SB, Toyoshima $\mathrm{H}$, et al. Race-ethnicity-specific waist circumference cutoffs for identifying cardiovascular disease risk factors. Am J Clin Nutr 2005;81:409-15.

16. Li WC, Chen IC, Chang YC, et al. Waist-to-height ratio, waist circumference and body mass index as indices of cardiometabolic risk among 36,642 Taiwanese adults. Eur J Nutr 2013;52:57-65.

17. Hsu HS, Liu CS, Pi-Sunyer FX, et al. The associations of different measurements of obesity with cardiovascular risk factors in Chinese. Eur J Clin Invest 2011:41:393-404.

18. Satoh $\mathrm{H}$, Kishi R, Tsutsui $\mathrm{H}$. Body mass index can similarly predict the presence of multiple cardiovascular risk factors in middle-aged Japanese subjects as waist circumference. Intern Med 2010;49:977-82.

19. Ryan MC, Fenster Farin HM, Abbasi F, et al. Comparison of waist circumference versus body mass index in diagnosing metabolic 
syndrome and identifying apparently healthy subjects at increased risk of cardiovascular disease. Am J Cardiol 2008;102:40-6.

20. Ying $X$, Song $Z Y$, Zhao CJ, et al. Body mass index, waist circumference and cardiometabolic risk factors in young and middle-aged Chinese women. J Zhejiang Univ Sci B 2010;11:639-46.

21. Cornier MA, Després JP, Davis N, et al. Assessing adiposity: a scientific statement from the American Heart Association. Circulation 2011;124:1996-2019.

22. Chen C, Lu FC, Department of Disease Control Ministry of Health, PR China. The guidelines for prevention and control of overweight and obesity in Chinese adults. Biomed Environ Sci 2004;17 (Suppl):1-36.

23. Xu Z, Qi X, Dahl AK, et al. Waist-to-height ratio is the best indicator for undiagnosed type 2 diabetes. Diabet Med 2013;30: e201-7.

24. Ramachandran A, Ma RC, Snehalatha C. Diabetes in Asia. Lancet 2010;375:408-18.

25. Chan JC, Malik V, Jia W, et al. Diabetes in Asia: epidemiology, risk factors and pathophysiology. JAMA 2009;301:2129-40.

26. $\mathrm{Xu} \mathrm{Y}$, Wang $\mathrm{L}, \mathrm{He} \mathrm{J}$, et al. Prevalence and control of diabetes in Chinese adults. JAMA 2013;310:948-59.

27. Bao C, Zhang D, Sun B, et al. Optimal cut-off points of fasting plasma glucose for two-step strategy in estimating prevalence and screening undiagnosed diabetes and pre-diabetes in Harbin, China. PLOS ONE 2015;10:e0119510.

28. Wang $H$, Qu $Q$, Tan LL, et al. Prevalence and determinants of diabetes and impaired fasting glucose among urban community-dwelling adults in Guangzhou, China. Diabetes Metab 2009;35:378-84.

29. Jia WP, Pang $C$, Chen $L$, et al. Epidemiological characteristics of diabetes mellitus and impaired glucose regulation in a Chinese adult population: the Shanghai Diabetes Studies, a cross-sectional 3-year follow-up study in Shanghai urban communities. Diabetologia 2007;50:286-92.

30. Xia Z, Wang Z, Cai Q, et al. Prevalence and risk factors of type 2 diabetes in the adults in Haikou city, Hainan island, China. Iran $J$ Public Health 2013;42:222-30.

31. Qi L, Feng L, Ding X, et al. Prevalence of diabetes and impaired fasting glucose among residents in the Three Gorges Reservoir Region, China. BMC Public Health 2014;14:1152.

32. Chen X, Yang W. Epidemic trend of diabetes in China: for the Xiaoren Pan Distinguished Research Award in AASD. J Diabetes Investig 2014;5:478-81.
33. Alberti KG, Zimmet P, Shaw J. International Diabetes Federation: a consensus on type 2 diabetes prevention. Diabet Med 2007;24:451-63.

34. Executive summary: standards of medical care in diabetes-2010. Diabetes Care 2010;33(Suppl 1):S4-10.

35. Hu FB, Manson JE, Stampfer MJ, et al. Diet, lifestyle and the risk of type 2 diabetes mellitus in women. N Engl J Med 2001;345:790-7.

36. He Y, Zhai F, Ma G, et al. Abdominal obesity and the prevalence of diabetes and intermediate hyperglycaemia in Chinese adults. Public Health Nutr 2009;12:1078-84.

37. Adeboye B, Bermano G, Rolland C. Obesity and its health impact in Africa: a systematic review. Cardiovasc J Afr 2012;23:512-21.

38. Wei $W$, Xin X, Shao B, et al. The relationship between anthropometric indices and type 2 diabetes mellitus among adults in north-east China. Public Health Nutr 2014;31:1-9.

39. Xiao X, Liu Y, Sun C, et al. Evaluation of different obesity indices as predictors of type 2 diabetes mellitus in a Chinese population. J Diabetes 2015;7:386-92.

40. Zeng Q, He Y, Dong S, et al. Optimal cut-off values of BMI, waist circumference and waist:height ratio for defining obesity in Chinese adults. Br J Nutr 2014;112:1735-44.

41. Hadaegh $F$, Zabetian $A$, Harati $H$, et al. Waist/height ratio as a better predictor of type 2 diabetes compared to body mass index in Tehranian adult men-a 3.6-year prospective study. Exp Clin Endocrinol Diabetes 2006;114:310-15.

42. Park SH, Choi SJ, Lee KS, et al. Waist circumference and waist-to-height ratio as predictors of cardiovascular disease risk in Korean adults. Circ J 2009;73:1643-50.

43. Hsieh SD, Yoshinaga $H$, Muto $T$. Waist-to-height ratio, a simple and practical index for assessing central fat distribution and metabolic risk in Japanese men and women. Int $J$ Obes Relat Metab Disord 2003;27:610-16.

44. Karakelides $\mathrm{H}$, Irving BA, Short KR, et al. Age, obesity and sex effects on insulin sensitivity and skeletal muscle mitochondrial function. Diabetes 2010;59:89-97.

45. Cowie CC, Rust KF, Byrd-Holt DD, et al. Prevalence of diabetes and impaired fasting glucose in adults in the US population: National Health and Nutrition Examination Survey 1999-2002. Diabetes Care 2006;29:1263-8.

46. Egbe EO, Asuquo OA, Ekwere EO, et al. Assessment of anthropometric indices among residents of Calabar, South-East Nigeria. Indian J Endocrinol Metab 2014;18:386-93.

47. Wells JC. Sexual dimorphism of body composition. Best Pract Res Clin Endocrinol Metab 2007;21:415-30. 